\title{
A PROSPECTIVE RANDOMIZED COMPARISON OF ULTRASOUND GUIDED PERCUTANEOUS CATHETER DRAINAGE AND PERCUTANEOUS NEEDLE ASPIRATION FOR THE TREATMENT OF LIVER ABSCESS
}

\author{
Indra Kumar Batham¹, Vivek Kumar Soni², Meenal Chandravanshi ${ }^{3}$ \\ 1Assistant Professor, Department of Radiodiagnosis, G. R. Medical College \& J. A. Group of Hospitals, Gwalior. \\ 2Junior Resident (PG Resident), Department of Radiodiagnosis, G. R. Medical College \& J. A. Group of Hospitals, Gwalior. \\ 3Junior Resident (PG Resident), Department of Radiodiagnosis, G. R. Medical College \& J. A. Group of Hospitals, Gwalior.
}

\section{ABSTRACT}

In recent years, image-guided percutaneous drainage has been increasingly used to treat liver abscesses with reported success rates ranging from $70-100 \%$. Although percutaneous placement of an indwelling catheter is the method most widely preferred to drain liver abscesses, recent studies have claimed needle aspiration to be a simpler, less costly, and equally effective mode of treatment.

\section{METHOD}

This is a single centred prospective randomized comparative study in patients of liver abscess treated by needle aspiration \& pigtail catheter drainage .A total no of 50 patient were included in the study which randomized into two groups; percutaneous needle aspiration (PNA) ( $n=25)$ and pigtail catheter drainage (PCD) $(n=25)$. The effectiveness of either treatment was measured in terms of duration of hospital stay, days to achieve clinical improvement, 50\% reduction in abscess cavity size and total/near total resolution of abscess cavity. Independent t-test was used to analyse these parameters.

\section{RESULTS}

Earlier clinical improvement $(\mathrm{P}=0.046)$ and $50 \%$ decrease in abscess cavity volume $(\mathrm{P}=0.0001)$ seen in the patients in $\mathrm{PCD}$ groups compared to those who underwent PNA. However, there was no significant difference between the duration of hospital stay or the time required for total or near-total resolution of cavity.

\section{CONCLUSION}

Percutaneous catheter drainage is a better modality as compared to percutaneous needle aspiration especially in larger abscesses, which are partially liquefied or with thick pus.

\section{KEYWORDS}

Liver Abscess, Percutaneous Catheter Drainage, Percutaneous Needle Aspiration.

HOW TO CITE THIS ARTICLE: Batham IK, Soni VK, Chandravanshi M. A prospective randomized comparison of ultrasound guided percutaneous catheter drainage and percutaneous needle aspiration for the treatment of liver abscess. J. Evolution Med. Dent. Sci. 2016;5(13):597-603, DOI: 10.14260/jemds/2016/136

\section{INTRODUCTION}

Liver abscess are the most common type of visceral abscess. A liver abscess occur when bacteria or protozoa entering directly from an injury through the blood vessels or by the way of the biliary ductal system \& destroy hepatic tissue producing a cavity which fills with infectious organisms, liquefied liver cells and leucocytes. Necrotic tissues then wall off the cavity from rest of the liver.

Liver abscess is found more commonly in men between 20 and 40 years of age, but can occur at any age. Approximately $60 \%$ are solitary and mainly located in the right lobe of the liver, as a result of the streaming of portal blood flow secondary to the fact that the right lobe is predominantly supplied by the superior mesenteric vein, and because most of the hepatic volume is in the right lobe.

Financial or Other, Competing Interest: None.

Submission 13-01-2016, Peer Review 25-01-2016,

Acceptance 01-02-2016, Published 15-02-2016.

Corresponding Author:

Dr. Vivek Kumar Soni,

01, Bhagwati Apartment,

380, Jiwaji Nagar, Thatipur

Gwalior, Madhya Pradesh

E-mail:dr.viveksoni.gmc@gmail.com

DOI: 10.14260/jemds/2016/136
When multiple abscesses are present, pyogenic or mixed is the most probable type. Patients usually present with a constant dull pain in the right upper quadrant of the abdomen which may be referred to the scapular region or the right shoulder. These patients usually have fever of between $38^{\circ} \mathrm{C}$ and $40^{\circ} \mathrm{C}$.

Liver abscesses, both amoebic and pyogenic, continue to be an important cause of morbidity and mortality in tropical countries. However, recent advances in interventional radiology, intensive care, progress in antibiotic therapy and liberal use of sonography and computerized tomography scanning of the abdomen have led to early diagnosis and treatment of patients with liver abscess, thus improving the patient outcome. Percutaneous drainage of liver abscess has been an important advancement in the treatment of pyogenic liver abscesses.

The primary mode of treatment of amoebic liver abscess is medical; however, as many as $15 \%$ of amoebic abscesses may be refractory to medical therapy.(1) Also, secondary bacterial infection may complicate $20 \%$ of amoebic liver abscesses.(2) In such patients and in patients with pyogenic liver abscesses, surgical drainage has been the traditional mode of treatment.(3) However, operative drainage is associated with significant $(10-47 \%)$ morbidity and mortality. $(4)$ 
In recent years, image-guided percutaneous drainage has been increasingly used to treat liver abscesses with reported success rates ranging from $70-100 \% .(5-7)$ Although, percutaneous placement of an indwelling catheter is the method most widely preferred to drain liver abscesses.(8) recent studies have claimed needle aspiration to be a simpler, less costly and equally effective mode of treatment.(9,10)

\section{METHOD}

This is a single centred prospective randomized comparative study in patients of liver abscess treated by needle aspiration and pigtail catheter drainage during January 2015 to November 2015. A total no. of 50 patients were included in the study, which randomized into two groups; percutaneous needle aspiration (PNA) ( $\mathrm{n}=25)$ and pigtail catheter drainage (PCD) $(n=25)$. There was predesigned proforma for collection of data.

\section{Inclusion Criteria}

The patients were selected from those attending the outpatient department and emergency department at the hospital. The age of patients varied from 15 to 65 years with most of the patients falling within the range from 28-45 years. All the patients diagnosed to have liver abscess clinically and radiologically [on ultrasonography (USG) and/or CT scan] were included in the study. Inclusion criteria were:

1. Abscess cavity size $>$ or $=5 \mathrm{~cm}$ in its largest diameter.

2. Liquefied/partially liquefied content.

3. Single cavities or multiple communicating abscess cavities.

4. Unilocular abscess cavity.

\section{Exclusion Criteria}

1. Multiple abscess and ascites.

2. Multiloculated or septate abscess.

3. Coagulation disorder.

4. Other foci of intra-abdominal abscess required surgery.

5. Liver abscess patients with suspected associated malignancy.

\section{SUBJECTS}

All the patients with liver abscess who were admitted between January 2015 and November 2015 were considered candidate for study. Informed consent was obtained from all participating patients. Fifty patients fitting the inclusion criteria were taken for the study. All the subjects satisfying the inclusion criteria underwent a detailed history taking and clinical examination. Following lab and imaging investigations carried out for every patient included in the study-

Complete hemogram.

Liver function tests.

Prothrombin time.

International normalized ratio.

Activated partial thromboplastin time.

Blood culture; amoebic serology.

Imaging.

\section{CXR}

Abdominal USG with or without CT scan of the abdomen other investigations as per specific indications in different patients. Randomization was done using computer software, according to a standardized previously reported protocol.(11)
The two sets of random numbers generated were assigned to the two intervention groups and sealed numbered envelopes were made with the serial number mentioned on the outside and intervention mentioned inside by a nonparticipating individual. Once a participating subject gave valid consent the pre-determined intervention was carried out as follows: The percutaneous procedures were carried out under local anesthesia (2\% lignocaine) with IV analgesia and sedation if required. The procedures were carried out under continuous real-time USG guidance using Aloka high resolution ultrasound machine.

\section{ANTIBIOTIC POLICY}

All the consenting patients were started on medical treatment as per our protocol. All the patients initially treated empirically with injection Cefazolin $1 \mathrm{~g}$ IV b.i.d. injection, Metronidazole $750 \mathrm{mg}$ IV every t.i.d. injection, Gentamicin $80 \mathrm{mg}$ IV b.i.d. and chloroquine $600 \mathrm{mg}$ for 2 days $1600 \mathrm{mg}$ is total dose for a day which is given in 2 divided doses and not $600 \mathrm{mg}$ q.i.d.) followed by $300 \mathrm{mg}$ for 19 days (Given in 2 divided doses). According to the culture and sensitivity report the empirical treatment was revised. However, patients were put on the same treatment, in whom pus culture was sterile. The antibiotics and metronidazole were given for duration of 10 and 14 days respectively.

\section{INTERVENTIONS \\ PERCUTANEOUS NEEDLE ASPIRATION (PNA)}

The patient was subjected to USG of the abdomen and the characteristics of the abscess cavity (IES) were recorded. Local anaesthesia was infiltrated at the proposed puncture site using a $16-G$ needle. Under real-time USG guidance and using $16-G$ comet tail needle the abscess cavity was entered and Complete evacuation of pus from cavity was attempted. A sample of pus was sent for Gram stain, culture, sensitivity and wet mount for Entamoeba histolytica trophozoites. A dressing was applied at the needle puncture site.

Follow-up scan done after 3 days of the procedure and size of the cavity was recorded. Sonography was repeated every 3 days initially in first week and the weekly for first month and then monthly until the cavity had either disappeared or had shown reduction or stasis in size with clinical recovery. Repeated aspiration was attempted for a maximum of 3 times for patients showing residual cavity size $>5 \mathrm{~cm}$ in followup USG. The failure of clinical improvement in terms of fever, abdominal pain and tenderness and leukocytosis or decrease in size of the abscess cavity $<5 \mathrm{~cm}$ after a third attempt of aspiration was taken as failure of needle aspiration. These patients underwent PCD but were not added to the PCD group.

\section{PIGTAIL CATHETER DRAINAGE PROCEDURE}

Pigtail catheter drainage procedure done under ultrasound guidance. The patient was subjected to USG of the abdomen and the characteristics of the abscess cavity (IES) were recorded. In drainage technique, an 8-14 French multiple sidehole pigtail catheter introduced into the abscess cavity by Seldinger technique. Careful localization of the abscess and proper selection of the entry site were pre-requisite for successful procedure. The optimal route of access was considered to the route in which catheter traversed the least possible amount of liver tissue and avoided bowel and pleura. 
Entry site was infiltrated with $2 \%$ lignocaine and by using a No. 11 blade a small stab was made on the anesthetized skin. Under real time sonographic guidance, the single puncture pigtail catheter (8-14 G) was inserted through the skin stab and guided to the center of the abscess cavity.

After proper positioning of catheter stylet was withdrawn and pus was aspirated with a $20 \mathrm{cc}$ syringe to reconfirm the position and the aspirated pus was sent to the lab for testing. Then the straightener was removed and the catheter was attached to a collecting bag via the supplied connector. After that catheter was secured to the skin using 10 Silk suture for continuous external drainage and the patient was sent back to the ward. When catheter output had stopped for 24 hours, a follow-up sonography was performed. If an abscess cavity was absent, the catheter was removed. If a residual cavity was present, the catheter was flushed with saline and aspirated until the return was clear.

Residual loculations of abscess were treated with catheter repositioning and aspiration. Further sonography was performed 3 days later and the catheter was removed if the catheter had remained unproductive or there is no residual collection. Otherwise, the catheter was left in situ until catheter output had stopped. Sonography was repeated every 3 days initially in first week and then weekly for first month and then monthly until the cavity had either disappeared or had shown reduction or stasis in size with clinical recovery.

\section{PATIENT FOLLOW-UP AND OUTCOME}

All patients underwent clinical follow-up and monitoring during daily rounds until they were discharged from the hospital. Follow-up sonography was performed 24 hours after intervention and repeated every 3 days in first week and the size of the abscess was recorded. Criteria for successful treatment were clinical subsidence of infection and sonographic evidence of abscess resolution, such as disappearance or marked decrease in the abscess cavity (More than $50 \%$ reduction of longest diameter before treatment). After discharge from the hospital, patients underwent followup evaluations in the outpatient clinic at least once a week during treatment and biweekly until 6 months from the beginning of the treatment.

In patients who underwent PCD, the clinical and laboratory parameters of the patient recorded everyday. Daily output of the catheter was measured and the catheter was flushed with $20 \mathrm{cc}$ of normal saline (This volume was deducted from the total drainage). Stable patients discharged with a catheter underwent follow-up sonography until there was no catheter output for 24 hours and then the catheter was removed. A decision to remove the pigtail catheter was made when the total drainage from the catheter decreased to less than $10 \mathrm{~mL} / 24 \mathrm{~h}$ for two consecutive days. Patient outcome in terms of length of hospital stay, complications related to the procedure and treatment failure and death were recorded. All the data recorded in predesigned printed proforma.

\section{MATERIAL}

A predesigned proforma.

Surgery and radiodiagnosis text books for reference.

Journals and publications available in college library as well as on internet for comparison and references.

\section{STATISTICAL ANALYSIS}

The effectiveness of either treatment was measured in terms of:

Duration of hospital stay;

Days to achieve clinical improvement;

Days to achieve $50 \%$ reduction in abscess cavity size;

Days to achieve total/near total resolution of abscess cavity.

Independent t-test was used to analyze these parameters. The level of significance was set at $\mathrm{P}<0.05$.Volume of abscess cavity and duration of drainage (applicable to PCD group only) were also analyzed and range and mean values were calculated for both the parameters.

\section{RESULTS}

A total of 50 patients randomized into two groups of 25 each were included in the study. The following observations were made.

\section{General Characteristics}

The age of the patients ranging from 15 years to 65 years. Maximum no. of the patients falling within the age range from 31-40 years (24 patients). The second most common age group was 21-30 years (16 patients) and the number of patients was less in extremes of age. There were 43 male and 7 female patients with liver abscess involved in the study. The male to female ratio was 6:1.

\section{Symptoms and Signs}

It was observed that pain in the right upper quadrant of the abdomen was the most common symptom, found in $92 \%$ of the cases (Table 1).

\section{Laboratory Data}

It was observed that 39 of 50 patients (78\%) had leukocytosis. Elevation of serum alkaline phosphatase was also observed in $76 \%$ of the patients. Amoebic serology positivity $(>0.90$, EIA) was found in $58 \%$ of the patients (Table 2 ).

\section{Pus Culture}

Pus aspirated from all abscesses was sent for culture and sensitivity. Cultures were found to be positive in 14 of 50 (28\%) of the cases. The rest were sterile (Table 3).

\section{Microbiology}

Among the pus culture positive cases Escherichia coli was isolated most frequently i.e. 6 of 14 culture positive patients (Table 4).

\section{Type of Abscess}

Amoebic liver abscesses were encountered more frequently (58\%) compared to pyogenic (22\%), amoebic abscesses with secondary bacterial infection $(6 \%)$ and abscesses of indeterminate etiology (14\%) (Table 5 and 6).

\section{Location of the Abscess}

The majority (about 82\%) of the abscesses were located in the right lobe of liver, $10 \%$ in the left and $8 \%$ in both lobes (Figure 1).

\section{Number of Abscess}

Solitary liver abscess cavity seen in $72 \%$ cases, whereas the rest of the patients had multiple abscesses.

\section{Volume of the Abscess}

It was observed that the volume of the abscess cavities was mostly between $150-350 \mathrm{~mL}$ with a range of $90 \mathrm{cc}$ to $780 \mathrm{cc}$ (Table 7). 


\section{Interventions and their Results}

A total of 50 patients underwent either of the two percutaneous procedures randomly and their response to treatment was recorded and analyzed. Pigtail percutaneous drainage was successful in all the 25 cases. On the other hand, image-guided needle aspiration was successful only in 19 of 25 patients $(\mathrm{P}=0.006)$. Out of these 19 patients successfully treated, 6 patients required only one aspiration, 10 required two aspirations, and 3 required three aspirations. The 7 patients who did not show clinical improvement and/or decrease in cavity size despite 3 aspirations were taken as failures. In the PNA group, on comparing the cavity volumes the mean cavity volume in those who were successfully treated was $220 \mathrm{cc}$, which was significantly less than those failing treatment; the mean volume being $403.6 \mathrm{cc}$. Earlier clinical improvement $(\mathrm{P}=0.046)$ and $50 \%$ decrease in abscess cavity volume $(\mathrm{P}=0.0001)$ seen in the patients in $\mathrm{PCD}$ groups compared to those who underwent PNA. However, there was no significant difference between the duration of hospital stay or the time required for total or near-total resolution of cavity (Table 8).

\begin{tabular}{|c|c|c|}
\hline SYMPTOMS & $\begin{array}{c}\text { NO. OF } \\
\text { PATIENT }\end{array}$ & PERCENTAGE \% \\
\hline $\begin{array}{c}\text { Right upper quadrant } \\
\text { pain }\end{array}$ & 46 & 92 \\
\hline Weakness & 44 & 88 \\
\hline Fever & 43 & 86 \\
\hline Anorexia & 41 & 82 \\
\hline Weight loss & 26 & 52 \\
\hline Night sweats & 25 & 50 \\
\hline Nausea/vomiting & 17 & 34 \\
\hline Chills/rigors & 15 & 30 \\
\hline Cough & 12 & 24 \\
\hline Right shoulder pain & 10 & 20 \\
\hline Diarrhea & 6 & 12 \\
\hline Dyspnea & 4 & 8 \\
\hline TABLE 1: SYMPTOMS IN ORDER OF DECREASING \\
\multicolumn{2}{|c|}{ FREQUENCY } \\
\hline
\end{tabular}

Pain in the right upper quadrant of the abdomen (92\%) was the most common symptom followed by weakness (88\%) and fever $(86 \%)$.

\begin{tabular}{|c|c|c|}
\hline ETIOLOGY & $\begin{array}{c}\text { AMOEBIC } \\
\text { SEROLOGY } \\
\text { RESULT }\end{array}$ & $\begin{array}{c}\text { PUS CULTURE } \\
\text { RESULT }\end{array}$ \\
\hline AMOEBIC & + & - \\
\hline PYOGENIC & - & + \\
\hline $\begin{array}{c}\text { AMOEBIC WITH } \\
\text { SECONDARY } \\
\text { INFECTION }\end{array}$ & + & + \\
\hline INDETERMINATE & - & - \\
\hline \multicolumn{2}{|c|}{ TABLE 2: LABORATORY DATA } \\
\hline
\end{tabular}

\begin{tabular}{|c|c|c|c|c|}
\hline & AMOEBIC & PYOGENIC & MIXED & INDETERMINATE \\
\hline PNA & 16 & 4 & 1 & 4 \\
\hline PCD & 13 & 7 & 2 & 3 \\
\hline \multicolumn{5}{|c|}{ TABLE 3: LABORATORY DATA } \\
\hline
\end{tabular}

PCN, percutaneous needle aspiration PCD, percutaneous catheter drainage.
Amoebic serology positivity ( $>0.90$, EIA) was found in $58 \%$ of the patients. Pus aspirated from all abscesses was sent for culture and sensitivity. Cultures were found to be positive in 14 of $50(28 \%)$ of the cases. The rest were sterile.

\begin{tabular}{|c|c|c|c|}
\hline \multicolumn{2}{|c|}{ MICROBIOLOGY } & NUMBER & $\begin{array}{c}\text { PERCENTAGE } \\
\%\end{array}$ \\
\hline \multicolumn{2}{|c|}{ No growth } & 36 & 72 \\
\hline \multirow{4}{*}{$\begin{array}{c}\text { Cultural } \\
\text { positive }\end{array}$} & Klebsiella spp. & 4 & 8 \\
\cline { 2 - 4 } & $\begin{array}{c}\text { E coli } \\
\text { speudomonas }\end{array}$ & 6 & 12 \\
\cline { 2 - 4 } & S. aureus & 2 & 4 \\
\hline
\end{tabular}

TABLE 4: MICROBIOLOGY (AEROBIC CULTURES WERE CONSIDERED NEGATIVE AFTER 48 H OF INCUBATION)

Pus aspirated from all abscesses was sent for culture and sensitivity. Cultures were found to be positive in 14 of 50 (28\%) of the cases. The rest were sterile. Among the pus culture positive cases Escherichia coli was isolated most frequently, i.e. 6 of 14 culture positive patients.

\begin{tabular}{|c|c|c|}
\hline ETIOLOGY & $\begin{array}{c}\text { AMOEBIC } \\
\text { SEROLOGY } \\
\text { RESULT }\end{array}$ & $\begin{array}{c}\text { PUS CULTURE } \\
\text { RESULT }\end{array}$ \\
\hline AMOEBIC & + & - \\
\hline PYOGENIC & - & + \\
\hline AMOEBIC WITH & + & + \\
SECONDARY & & - \\
INFECTION & - & - \\
\hline INDETERMINATE & - & \\
\hline \multicolumn{2}{|c|}{ TABLE 5: TYPE OF ABSCESS (SHOWING AMOEBIC } \\
SEROLOGY AND PUS CULTURE)
\end{tabular}

Amoebic liver abscesses were encountered more frequently (58\%) compared to pyogenic (22\%), amoebic abscesses with secondary bacterial infection $(6 \%)$ and abscesses of indeterminate etiology (14\%).

\begin{tabular}{|l|c|c|c|c|}
\hline & AMOEBIC & PYOGENIC & MIXED & INDETERMINATE \\
\hline PNA & 16 & 4 & 1 & 4 \\
\hline PCD & 13 & 7 & 2 & 3 \\
\hline \multicolumn{4}{|c|}{ TABLE 6: TYPE OF ABSCESSES IN EACH GROUP } \\
\hline
\end{tabular}

PCN, percutaneous needle aspiration PCD, percutaneous catheter drainage.

\begin{tabular}{|c|c|}
\hline Volume of Cavity & No. of Patient \\
\hline $50-100$ & 1 \\
\hline $101-150$ & 2 \\
\hline $151-200$ & 8 \\
\hline $201-250$ & 11 \\
\hline $251-300$ & 9 \\
\hline $301-350$ & 8 \\
\hline $351-400$ & 4 \\
\hline $401-450$ & 1 \\
\hline $451-500$ & 2 \\
\hline $501-550$ & 2 \\
\hline $551-600$ & 1 \\
\hline $601-650$ & 0 \\
\hline $651-700$ & 0 \\
\hline $701-750$ & 0 \\
\hline 751-800 & 1 \\
\hline PATIENTS IN EACH GROUP \\
\hline
\end{tabular}


It was observed that the volume of the abscess cavities was mostly between $150-350 \mathrm{~mL}$ with a range of $90 \mathrm{cc}$ to $780 \mathrm{cc}$

\begin{tabular}{|c|c|c|c|c|c|}
\hline \multicolumn{6}{|c|}{ Treatment Group } \\
\hline \multirow[b]{2}{*}{ Parameter } & \multicolumn{2}{|c|}{$\begin{array}{c}\begin{array}{c}\text { Pigtail Catheter Drainage } \\
(n=30)\end{array} \\
\end{array}$} & \multicolumn{2}{|c|}{$\begin{array}{l}\text { Percutaneous Needle Aspiration } \\
\qquad(n=30)\end{array}$} & \multirow[b]{2}{*}{ P Value } \\
\hline & $\begin{array}{c}\text { No. of } \\
\text { patients }\end{array}$ & $\begin{array}{c}\text { Value(c.c.) } \\
\text { Min-max } \\
\text { Mean +/- }\end{array}$ & $\begin{array}{c}\text { No. of } \\
\text { patients }\end{array}$ & $\begin{array}{c}\text { Value(c.c.) } \\
\text { Min-max } \\
\text { Mean +/- } \\
\end{array}$ & \\
\hline Volume of the largest cavity(c.c) & 25 & $\begin{array}{c}150-710 \\
(328+/-122)\end{array}$ & 25 & $\begin{array}{c}90-680 \\
(269+/-123)\end{array}$ & 0.095 \\
\hline Success & 25 & $100 \%$ & 19 & $76 \%$ & 0.006 \\
\hline Hospital Stay(days) & 25 & $\begin{array}{c}4-25 \\
10.6+/-4.1\end{array}$ & 25 & $\begin{array}{c}5-22 \\
11.6+/-5.3\end{array}$ & 0.459 \\
\hline Clinical improvement & 25 & $\begin{array}{c}3-10 \\
4.6+/-1.4\end{array}$ & 19 & $\begin{array}{c}2-10 \\
5.5+/-1.7\end{array}$ & 0.046 \\
\hline $\begin{array}{l}\text { Time for } 50 \% \text { reduction in } \\
\text { cavity size(days) }\end{array}$ & 25 & $\begin{array}{c}3-10 \\
(4.9+/-1.6)\end{array}$ & 25 & $\begin{array}{c}3-11 \\
(8.1+/-2.3)\end{array}$ & 0.0001 \\
\hline $\begin{array}{l}\text { Time for total or near total } \\
\text { resolution of cavity (weeks) }\end{array}$ & 25 & $\begin{array}{c}8-24 \\
10.9+/-4.1)\end{array}$ & 25 & $\begin{array}{c}8-24 \\
(10.1+/-4.2)\end{array}$ & 0.498 \\
\hline Duration of drainage (days) & 25 & $\begin{array}{c}4-24 \\
(9.4+/-4.0)\end{array}$ & NA & NA & NA \\
\hline & & & RESULTS & & \\
\hline
\end{tabular}

CC, cubic centimeter; SD, standard deviation; NA, not applicable; A total of 50 patients underwent either of the two percutaneous procedures randomly and their response to treatment was recorded and analyzed. Pigtail percutaneous drainage was successful in all the 25 cases. On the other hand, image-guided needle aspiration was successful only in 19 of 25 patients $(\mathrm{P}=0.006)$. Out of these 19 patients successfully treated, 6 patients required only one aspiration, 10 required two aspirations, and 3 required three aspirations. The 7 patients who did not show clinical improvement and/or decrease in cavity size despite 3 aspirations were taken as failures. In the PNA group, on comparing the cavity volumes the mean cavity volume in those who were successfully treated was $220 \mathrm{cc}$, which was significantly less than those failing treatment; the mean volume being $403.6 \mathrm{cc}$. Earlier clinical improvement $(\mathrm{P}=0.046)$ and $50 \%$ decrease in abscess cavity volume $(\mathrm{P}=0.0001)$ seen in the patients in $\mathrm{PCD}$ groups compared to those who underwent PNA. However, there was no significant difference between the duration of hospital stay or the time required for total or near-total resolution of cavity.

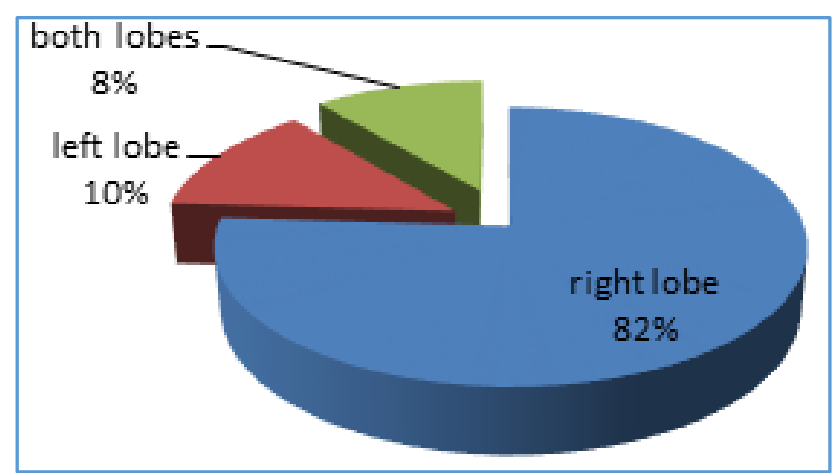

FIG. 1: LOCATION OF THE ABSCESS
The majority (about $82 \%$ ) of the abscesses were located in the right lobe of liver, $10 \%$ in the left and $8 \%$ in both lobes.

\section{DISCUSSION}

Liver abscesses, both amoebic and pyogenic continue to be an important cause of morbidity and mortality in the tropical countries. Patients usually present late when the liver abscess attains a large size. Percutaneous drainage (Either needle aspiration or catheter drainage) with systemic antibiotics has become the preferred treatment for the management of liver abscesses. In contrast for amoebic abscesses, the primary mode of treatment is medical; however, as many as $15 \%$ of these may be refractory to medical therapy, while $20 \%$ may be complicated by secondary bacterial infection. Such amoebic abscesses and those involving left lobe, or those with impending rupture also need to be drained. Although, PCD is a preferred method most widely used to drain liver abscesses.

Pyogenic liver abscess which used to be mainly tropical in location is now more common due to increased biliary interventions, stenting. The most frequently affected age group is in the third and fourth decade.

In our study clinical presentation of the patients are fever (86\%), right upper quadrant pain and tenderness (92\%) and hepatomegaly (76\%). In the studies, $82 \%$ of the abscesses are located in the right lobe of liver and $72 \%$ of our patients had solitary abscesses. We encountered multiple liver abscesses in $28 \%$ of the patients.

The most frequently isolated bacteria on pus culture is Escherichia coli (42\%) followed by Klebsiella species (28\%).

Many solitary and some carefully selected macroscopic multiple abscesses are amenable to percutaneous abscess drainage. Surgical drainage is usually reserved for patients who have failed percutaneous drainage, those who require surgery for management of underlying problems, and some patients with multiple macroscopic abscesses.(12) 
The major advantages of PNA over PCD are: 1 ) it is less invasive and less expensive; 2) avoids problems related to catheter care; and 3) multiple abscess cavities can be aspirated easier in the same setting. $(9,10)$

The success rate of PNA in the literature varies from 79$100 \% .(9,13)$ In our study the success rate after single aspiration is $24 \%$, after second aspiration $64 \%$ and after third aspiration it is $76 \%$. Although, needle aspiration is a much simpler procedure when compared to catheter drainage repeated procedures are quite unpleasant and traumatic for the patients and may not be acceptable to many. Even after repeated aspirations the success rate is far from being $100 \%$. Therefore, those patients who failed after a third aspiration attempt are offered catheter drainage.

In contrast to some of the earlier reports that show that the initial size of the abscess cavity did not affect the ultimate outcome.(10,14) larger abscesses are more difficult to evacuate completely in one attempt, necessitating subsequent aspiration.(15) The average volume of the abscess in patients in whom PNA failed was significantly larger than the average volume of the abscess in patients who could be successfully treated with PNA.

Another important reason for failure of needle aspiration is the inability to completely evacuate the thick viscous pus that may be present in some of the abscesses. Rapid reaccumulation of pus in the abscess is another reason for failure of needle aspiration.(16)

Placement of an indwelling drainage catheter addresses all three of these issues as it provides continuous drainage, drains thick pus because of wider caliber catheter and prevents re-accumulation. This explains the higher success rates of PCD. $(9,15,13,17)$

The only reasons for failure of PCD as reported in some of the earlier series.(18,19) have been either thick pus not amenable to percutaneous drainage (this can be overcome by placement of a wider bore catheter) or premature removal of drainage catheter. No recurrence occurred during the follow up period. However, both treatment modalities resulted in rapid clinical relief with most patients showing resolution of signs and symptoms within the first 3-4 days of the procedure.

The time required for $50 \%$ reduction in the cavity size is significantly less in the PCD compared to PNA group (4.9 days and 8.1 days respectively); however, time required for total or near-total resolution of the abscess cavity did not show any significant difference. It can be concluded that the abscess cavities showed faster collapse during the initial period in the PCD group but it did not have an advantage as far as total or near-total resolution of cavity is concerned.

Similar observations were recorded by other investigators as well.(8,15) Complications such as hemorrhage, pleural effusion/empyema, persistent bile drainage, catheter displacement, sepsis, etc., have been reported with both PNA.(8) and PCD.(20) Described the much lower incidence of complications with PNA than with PCD as one of the major advantages of needle aspiration over catheter drainage. Although secondary bacterial infection remains a possibility with indwelling drainage catheters this complication has been rarely reported in liver abscess.in our study we did not come through any of the above mentioned complications in patients of each group.

\section{Summary Box}

What is already known,

- Currently image-guided percutaneous treatment (Aspiration or catheter drainage) has replaced surgical intervention as the procedure of choice.

- If performed carefully both the procedures are safe with minimal complications what the new findings are:

- Percutaneous catheter drainage is a better modality as compared to percutaneous needle aspiration.

- With repeated aspiration there is increase chances of success of treatment by percutaneous needle aspiration.

- The percutaneous catheter drainage group shows significantly earlier clinical improvement $(\mathrm{P}=0.046)$ and less time for $50 \%$ reduction in abscess cavity $(\mathrm{P}=0.0001)$.

- There was no significant advantage of catheter drainage over needle aspiration in terms of duration of hospital stay and time needed for total or near total resolution of abscess cavity.

- Catheter drainage is better for large cavity while needle aspiration is better for small abscess cavity showing complete or near complete liquefied contents.

\section{REFERENCES}

1. Thompson JE, Jr; Forlenza S; Verma R. Amoebic liver abscess: a therapeutic approach. Rev Infect Dis 1985;7:171-179. [PubMed]

2. Sherlock S, Dooley J. 9th ed. Oxford: Blackwell Sci Pub; 1993. Diseases of the liver and biliary system; pp. 471502.

3. Theron P. Surgical aspects of amoebiasis. Br Med J 1947;2:123-126. [PMC free article] [PubMed]

4. Satiani B, Davidson ED. Hepatic abscesses: improvement in mortality with early diagnosis and treatment. Am J Surg 1978;135:647-650. [PubMed]

5. Gerzof SG, Johnson WC, Robbins AH, et al. Intrahepatic pyogenic abscesses: treatment by percutaneous drainage. Am J Surg 1985;149:487-494. [PubMed]

6. Attar B, Levendoglu H, Cuasay NS. CT-guided percutaneous aspiration and catheter drainage of pyogenic liver abscesses. Am J Gastroenterol 1986 ;81:550-555. [PubMed]

7. Seeto RK, Rockey DC. Pyogenic liver abscess. Changes in etiology, management and outcome. Medicine (Baltimore) 1996;75:99-113. [PubMed]

8. Singh JP, Kashyap A. A comparative evaluation of percutaneous catheter drainage for resistant amoebic liver abscesses. Am J Surg 1989;158:58-62. [PubMed]

9. Baek SY, Lee MG, Cho KS, etal. Therapeutic percutaneous aspiration of hepatic abscesses: effectiveness in 25 patients. AJR 1993;160:799-802. [PubMed]

10. Giorgio A, Tarantino L, Mariniello N, et al. Pyogenic liver abscesses: 13 years of experience in percutaneous needle aspiration with US guidance. Radiology 1995;195:122-124. [PubMed]

11. Urbaniak GC, Plous S. Research randomizer (version 3.0) [Computer software] [Retrieved on November 7, 2011] from http://www.randomizer.org .

12. Huang CJ, Pitt HA, Lipsett PA, et al. Pyogenic hepatic abscess. Changing trends over 42 years. Ann Surg 1996;223:600-607. Discussion 607-609. [PMC free article] [PubMed] 
13. Saraswat VA, Agarwal DK, Baijal SS, et al. Percutaneous catheter drainage of amoebic liver abscess. Clin Radiol 1992;45:187-189. [PubMed]

14. Stain SC, Yellin AE, Donovan AJ, et al. Pyogenic liver abscess. Modern treatment. Arch Surg 1991;126:991996. [PubMed]

15. Rajak CL, Gupta S, Jain S, et al. Percutaneous treatment of liver abscesses: needle aspiration versus catheter drainage. AJR 1998;170:1035-1039. [PubMed]

16. Dietrick RB. Experience with liver abscess. Am J Surg 1984;147:288-291. [PubMed]

17. Gupta SS, Singh O, Sabharwal G, et al. Catheter drainage versus needle aspiration in management of large $(>10 \mathrm{~cm}$ diameter) amoebic liver abscesses. ANZ J Surg 2011; 81:547-551. [PubMed]
18. Bertel CK, Van Heerden JA, Sheedy PF. Second treatment of pyogenic hepatic abscesses. Surgical vs percutaneous drainage. Arch Surg 1986;121:554-558. [PubMed]

19. Van Sonnenberg E; Ferrucci JT, Jr; Mueller PR; et al. Percutaneous drainage of abscesses and fluid collections: technique, results and applications. Radiology 1982; 142:1-10. [PubMed]

20. Do H, Lambiase RE, Deyoe L, et al. Percutaneous drainage of hepatic abscesses: comparison of results in abscesses with and without intrahepatic biliary communication. AJR 1991;157:1209-1212. [PubMed] 